\title{
5
}

\section{Serial Team Teaching and the Evolving Scholarship of Learning: Students' Perspective}

\author{
Melody Neumann, Charly Bank, Scott Browning, Jim Clarke, Jason Harlow, David Harrison, \\ Karen Ing, Lena Kushnir, Cecilia Kutas, John Pitre, Ruxandra Serbanescu, Marty Wall, \& Ron \\ Wilson \\ Faculty Learning Community \\ University of Toronto
}

Faculty and students at the University of Toronto were surveyed and interviewed to form a case study of serial team teaching, in which multiple instructors take turns teaching a segment of the same course in sequence. Student opinions ranged from slightly opposed to slightly in favour of team teaching overall. When asked about specific aspects of team teaching, students who liked it overall tended to like all aspects of it, and did not identify those disadvantages in student experience anticipated by the faculty. In general, students in upper years were less supportive of team teaching than were students in their first and second years.

\section{Introduction}

Tn Spring 2006 we conducted a faculty survey 1 to investigate team teaching methods within the Faculty of Arts and Science at the St. George Campus of the University of Toronto (FLC-University of Toronto, 2006). The survey had two stages; the first identified departments offering courses that were team taught, and the second consisted of individual interviews of faculty involved in team teaching. The goal of the survey was to determine which team teaching models were currently in use for undergraduate courses on this campus, and to use the wealth of knowledge and experience available there to gain a bet- ter understanding of these models.

We interviewed more than 60 faculty members from 15 departments in a voluntary survey. The data we collected and analyzed comprised both factual information (enrolment statistics, number of instructors involved, and a team teaching model) and interpretive data (perceived advantages/disadvantages, faculty impressions of student experience, and recommendations/warnings).

The most inclusive definition of a "team taught" course is: any course with more than one instructor. In our context we identified three categories, one of them divided into two sub-categories: 
A. Two or more instructors share all or most classes (Gurman, 1989).

B. Serial: a "tag team:"

i. The instructors alternate sequentially with each instructor teaching just one uninterrupted segment of the course (e.g., one quarter or one term).

ii. The instructors alternate every couple of weeks or so, teaching more than one segment of a course (Morlock et al., 1998).

C. Parallel: each section of the course is taught by a separate instructor (Ennis, 1986).

Most courses at the University of Toronto follow category B, subgroup i.

Some of the most interesting findings of the faculty survey were the perceived advantages and disadvantages of serial team teaching for the students. Faculty felt that students benefit from the diversity of expertise and perspectives gained (Crossman \& Behrens, 1992) in serial team-taught courses. However, most instructors see this as a benefit for higher-year rather than lower-year courses. The main perceived disadvantages were in the area of student experience, specifically the lack of continuity in content, lack of communication between team members, difference in teaching styles, and reduced rapport with the students.

The literature on team teaching in higher education tends to focus on model A above where two or more instructors share all or most classes (Anderson \& Speck, 1998; Kezar, 2000; McDaniel \& Colarulli, 1997), yet the predominant model found in our Faculty was model B. Anecdotal evidence indicates that other institutions are also adopting model B. Therefore, we thought it important to ascertain the student perspective on the application of this model.

\section{Online Student Survey}

In Spring 2007, we conducted a voluntary survey of student opinion on a website frequented by 4000 University of Toronto Life Sciences students (http://biome.utoronto.ca). The survey asked for the students' year of study, and the answers to 10 questions measured on a five point Likert scale: (strongly) agree, neutral, disagree (strongly). Table 1 lists the questions. Questions 2 and 3 asked about students' personal satisfaction with their grades, and the perceived quality of their university experience. Questions 4 to 9 dealt with specific aspects of serial teamtaught courses; these aspects had been identified as key advantages or disadvantages to team teaching by the previous faculty survey (FLC-University of Toronto, 2006). Questions 10 and 11 probed students' overall satisfaction. One hundred sixty-three students completed the survey, ranging from first- to fourth-year undergraduates.

\section{Results}

The data set was considered from several perspectives. As a first step, we sought correlation between student experience and expectation to use as a barometer for further monitoring. Next, we looked for a correlation across all responses, and finally, results were analyzed by students' academic year of study.

The data we collected were found to be discrete rather than following a normal distribution. To measure the degree of association between a pair of discrete variables and to assess the significance of such association, we used non-parametric statistical analysis (Kendall's Tau-B; see Kendall, 1962). In looking for a correlation between students' self-reported quality of university experience and expected grades based on studying, we noted that when all students were considered, very few rated their university experience higher than average, or stated their expected grades as high (Figure 1). Most responses clustered in the midpoint of the Likert scale, but showed a clear correlation between perceived experience and grade expectation.

\section{Correlations Across All Responses}

Figure 2 depicts a matrix showing the correlation among all questions. The matrix is symmetric about the diagonal from top-left to bottom-right. Insignificant values ( $p$-value $>.05$ ) and values on this diago- 


\section{Table 1}

Questions in Faculty Learning Community's 2007 online student survey on student perspectives of team teaching at the University of Toronto. Questions 3 to 11 were answered using the following 5-point Likert scale: Strongly agree, Agree, Neutral, Disagree, Strongly Disagree.

1. How many course credits have you completed?
$<4$
$4-8.5$
9-13.5
$\geq 14$

2. Over all, the grades I am receiving in the courses I am taking this year are:

- much higher than expected based on my studying.

- better than expected given the amount of studying I am doing.

- on par with the amount of studying I am doing.

- lower than I expect based on the studying I do.

- much lower than I expect based on my studying.

3. Over all, my university experience this year has been positive.

4. Exposure to different teaching styles is an advantage of team teaching.

5. Exposure to different areas of expertise or opinions is an advantage of team teaching.

6. Exposure to a larger number of faculty members is an advantage of team teaching.

7. Transitions between different faculty members is an advantage of team teaching.

8. Team taught courses are well coordinated.

9. Course content is continuous without obvious interruptions in team taught courses.

10. Over all, I would like more of my courses to be team taught using the team teaching model.

11. Over all, my experience with team taught courses has been positive.

\section{Figure 1}

Quality of University Experience (SA = Strongly Agree, $\mathrm{A}=$ Agree, $\mathrm{N}=$ Neutral, $\mathrm{D}=$ Disagree and SD $=$ Strongly Disagree) versus grades expected based on studying. Each coloured square in this (and subsequent) figures records the number of students who indicated the corresponding response on the horizontal scale AND the corresponding response on the vertical scale. Note that most responses fall along the diagonal, which indicates a modest correlation in students' answers to the two questions.

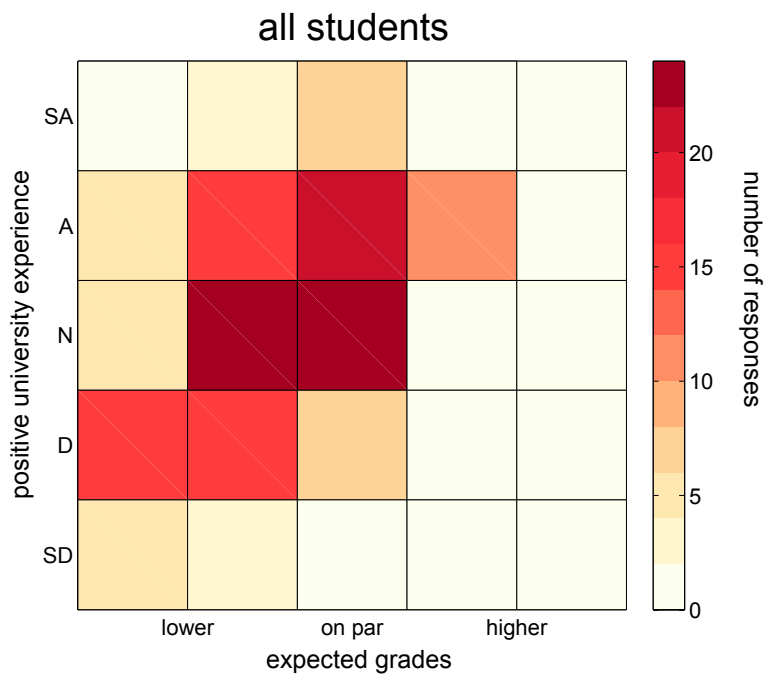




\section{Figure 2}

Correlations across all 11 questions on the Likert scale. "Not meaningful" indicates autocorrelations (on diagonal) or insignificant correlations (sigma $>0.05$ ). Each coloured square in this figure (in contrast to the other figures) shows how well the answers between two questions correlate. For example, the moderate correlation hinted at in Figure 1 shows up as orange hue for the correlation between questions 2 and 3. Many pairs of questions have a stronger hue, and thus an even better correlation.

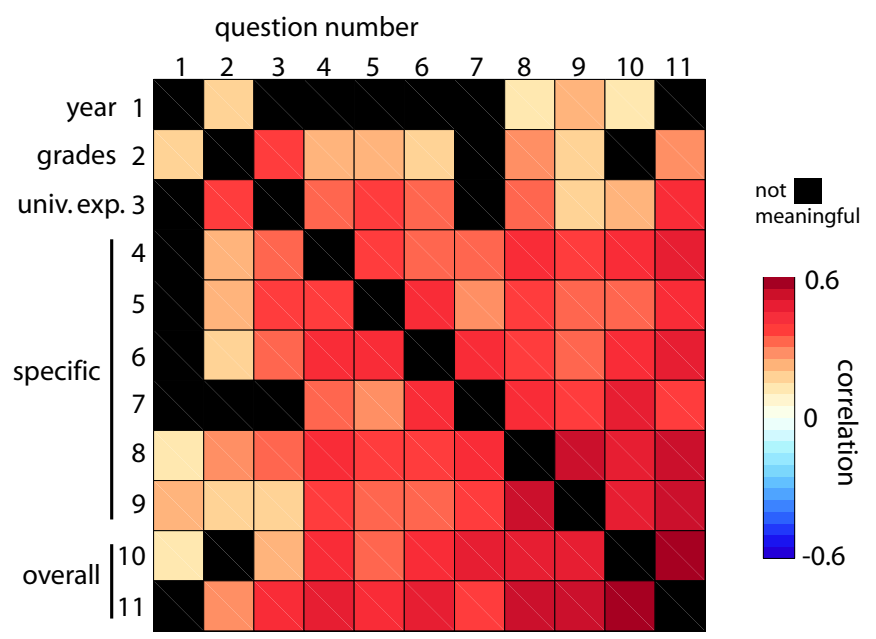

nal (where questions are mapped onto themselves) are blacked out. Although negative Tau values are possible, none were observed - a positive correlation was found across all survey questions. Therefore, the data in Figure 2 is indicative of a consistency in students' perspective: either a student likes all aspects of team teaching, or she/he likes nothing about it. In particular, this all-or-nothing view seems to link any aspect of serial team-teaching to students' expected grades and their perceived university experience.

\section{Analysis by Year}

When the results are analyzed by academic year, differences do emerge. The message changes most dramatically between first and fourth year students. In the first year the strongest correlation occurs between a negative experience and an expectation of low marks (Figure 3, left panel), while in the fourth year the strongest correlation occurs between a positive university experience regardless of expected grades (Figure 3, right panel). Indeed, a cluster of fourthyear students feel that their grades are acceptable despite their negative university experience, and yet others feel that their university experience is positive despite their low marks. We hypothesize that this dissociation between experience and grades expectation comes about with academic maturity. Those students who succeed academically feel good about their achievement and still show a strong association between experience and grades expectation. For others, the perception of their university experience becomes less dependent on their grades either because they have decided to have 'a good time' despite low grades, or they have dedicated themselves to getting good grades at the expense of 'a good time.'

\section{Student Perspectives}

Regarding student perspectives on team teaching, the majority of students did identify different areas of expertise (Q.5 80\% approve) and exposure to a larger number of faculty (Q.6 55\% approve, 29\% neutral) as advantages. However, most students did not pick up on the disadvantages proposed by faculty in our earlier study. The change in teaching styles (Q.4), expected to be jarring, was seen as negative by only $26 \%$ of respondents. Lack of course co-ordination 


\section{Figure 3}

Correlations between a positive university experience and expected grades, for first year $(\mathrm{N}=36)$ and fourth year $(\mathrm{N}=35)$ students.

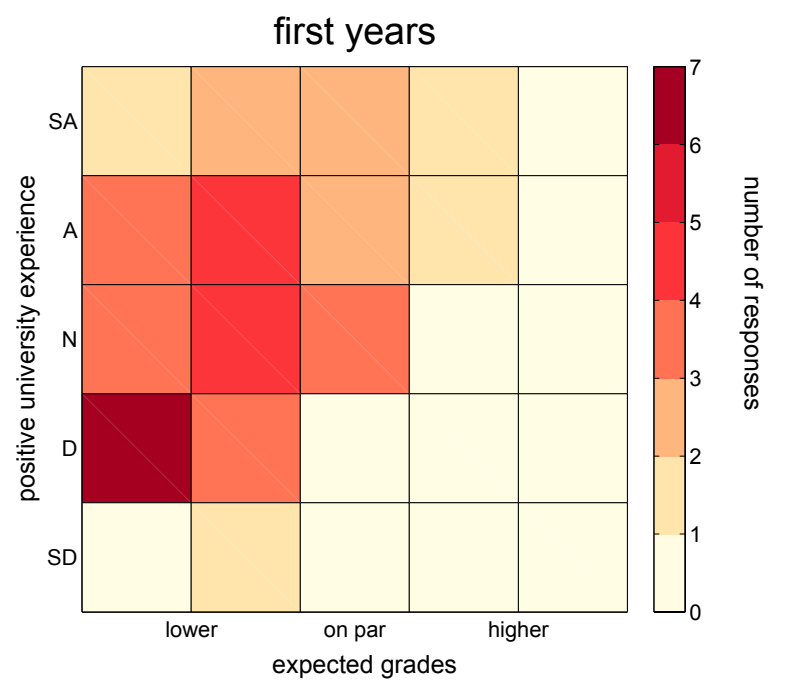

(Q.8) was reported as a negative aspect by $26 \%$ of students, and lack of continuity in content (Q.9) and faculty transitions (Q.7) were identified as negative elements by $40 \%$ and $43 \%$ of respondents, respectively. Overall, fourth-year students were less positive about serial team teaching then their first and second

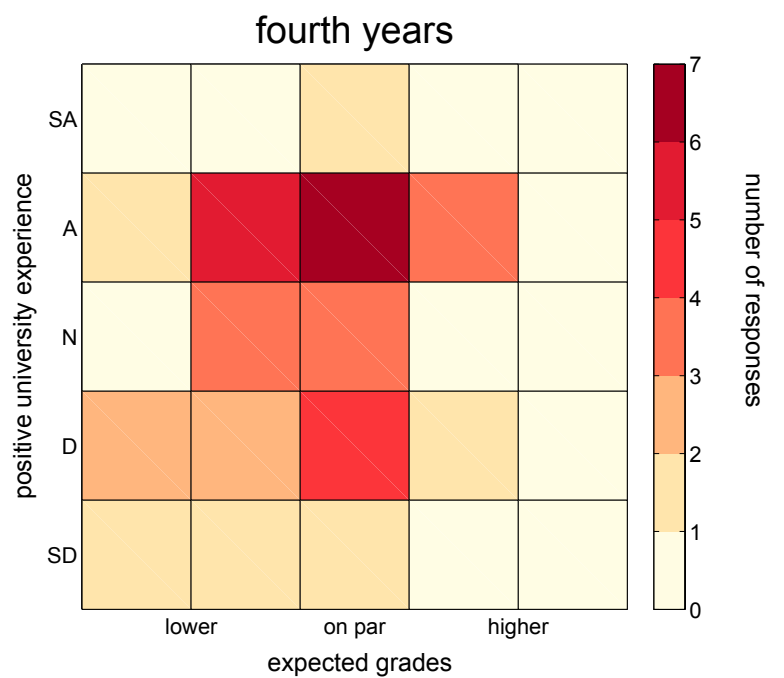

year counterparts (see Figure 4). Although faculty had expected that students who were more mature academically would benefit more from the diversified expertise and perspective of a multi-lecturer course, students in higher years are also more experienced with university life and may therefore have more de-

\section{Figure 4}

Correlations between year and support for serial team taught courses (question 11). Note how the response for each year (i.e. row) shifts from "neutral" for first and second years to "disagree" for higher years.

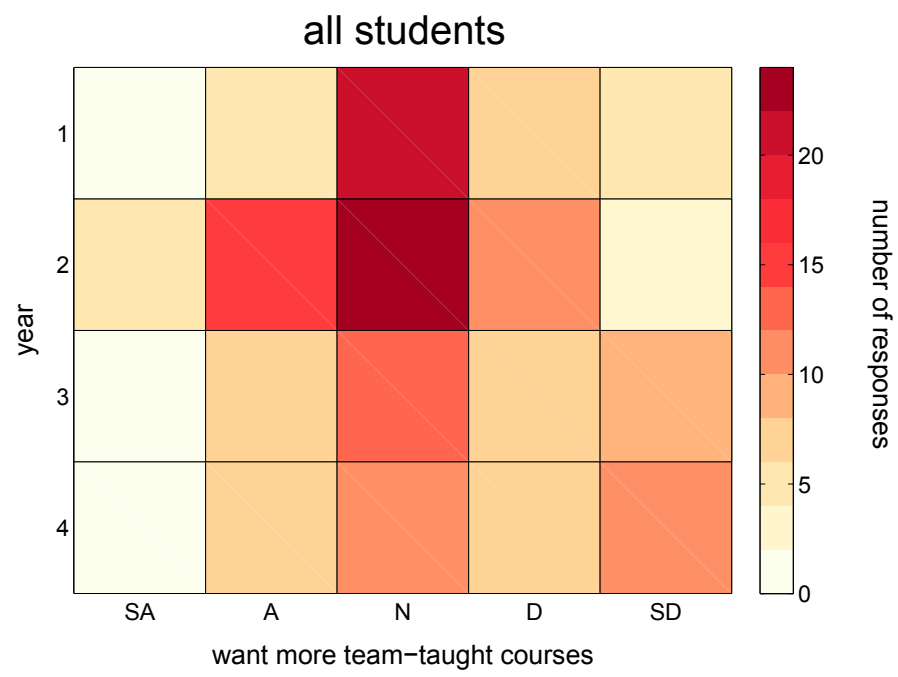


fined expectations as to their preferences in lecture mode.

\section{Case Study Summary and Outlook}

From the faculty perspective, the main advantage of team teaching is the diversity of expertise a multimember teaching team can provide. The main disadvantages pertain to lack of continuity in the student experience. Overall, faculty considered team teaching a good approach.

We note that our student survey was a case study with a limited number of voluntary responses and thus may not be representative of all student experiences with serial team teaching. However, some trends seem to emerge. Respondents of our student survey who like team teaching enjoy all aspects of it, and vice versa. Students' view of team teaching correlates with their satisfaction with the university experience. Overall, students did not identify faculty-anticipated disadvantages of team teaching such as discontinuity of content, lack of co-ordination, or dissimilar teaching styles. In addition, fourth-year students were less likely to be in favour of serial team teaching despite being less inclined to base their university experience on achieving high grades.

Our survey results open new questions. Do students with certain preferred learning styles think more positively about serial team teaching? Are upper-year students really less favourable of this model, and if yes, why? What can instructors do to make serial team teaching more effective, and improve student perceptions of this teaching model? Are students' grades the main variable defining their university experience, independent of mode of instruction? Answering such questions would require a larger sample of students, and possibly a more detailed survey of faculty and students across various institutions. We invite colleagues to share with us their and their students' experiences with serial team teaching.

\section{Acknowledgements}

We would like to thank all faculty and students who participated in our study, three anonymous reviewers for their thoughtful comments, past FLC members for their valuable input, and the Dean's office for ongoing support.

\section{References}

Anderson, R.S. \& Speck, B.W. (1998). Oh what a difference a team makes: Why team teaching makes a difference. Teaching and Teacher Education, 14(7), 671-686.

Arts \& Science. (2006). Faculty survey on team teaching. Retrieved on August 7, 2007, from http://faraday.physics.utoronto.ca/PVB/ FLC/TeamTeachingReport.pdf

Crossman, D.M. \& Behrens, S.G. (1992, February). Affective strategies for effective learning. Paper presented at the Annual Conference of the Association for Educational Communications and Technology, Washington, DC.

Ennis, R. (1986). Team teaching in adult basic education. Australian Journal of Adult Education, 26(3), 4-8.

FLC-University of Toronto. (2006). Team teaching: A survey of 50 courses in the Faculty of Arts and Science at the University of Toronto with more than one instructor. Retrieved August 7, 2007, from http://faraday.physics.utoronto. ca/PVB/FLC/TeamTeachingReport.pdf

Gurman, E.B. (1989). The effect of prior test exposure on performance in two instructional settings. The Journal of Psychology, 123(3), 275278.

Kendall, M.G. (1962). Rank correlation methods (3rd ed.). London: Griffin.

Kezar, A.J. (2000). Higher education trends (19992000): Teaching and learning. Eric Clearinghouse on Higher Education. US Department of 


\section{Education.}

McDaniel, E.A \& Colarulli, G.C. (1997). Collaborative teaching in the face of productivity concerns: The dispersed team model. Innovative Higher Education, 22(1), 19-35.

Morlock, H.C., Gaeddret, W.P., McCormick, N.B., Merrens, M.R., Shaffer, L.C. \& Zandi, T. (1998). A rotational format for team teaching introductory psychology. Teaching Psychology, 15(3), 144-145. 